\begin{tabular}{|c|l|}
\hline Title & $\begin{array}{l}\text { Modelling of stem biomass accumulation in Pinus densiflora seedlings exposed to aqueous phase OH radicals } \\
\text { generating mist }\end{array}$ \\
\hline Author(s) & Kubo, Takuya; Kobay ashi, Tsuy oshi \\
\hline Citation & $\begin{array}{l}\text { Ecological Modelling, 200(3-4), 467-474 } \\
\text { https://loi.org/10.1016/.ecolmodel.2006.08.014 }\end{array}$ \\
\hline Issue Date & 2007-01-24 \\
\hline Doc URL & http://hdl.handle.net/2115/18849 \\
\hline Type & article (author version) \\
\hline File Information & EM200-3-4.pdf \\
\hline
\end{tabular}

Instructions for use 


\title{
Modelling of stem biomass accumulation in Pinus densiflora seedlings exposed to aqueous-phase $\mathrm{OH}$ radicals generating mist
}

\author{
Takuya Kubo a,b,* and Tsuyoshi Kobayashic,d,e \\ a Graduate School of Environmental Earth Science, Hokkaido University, Sapporo, Hokkaido 060-0810, Japan \\ b FRCGC, JAMSTEC Yokohama Institute, Yokohama, Kanagawa 236-0001, Japan \\ c Faculty of Agriculture, Kagawa University, Mikicho, Kagawa 761-0795, Japan \\ d Institute of Low Temperature Science, Hokkaido University, Sapporo, Hokkaido 060-0819, Japan \\ e Center for Forest Decline Studies, Hiroshima Technoplaza, Higashi-Hiroshima, Hiroshima 739-0046, Japan
}

Keywords: hierarchical Bayesian modelling; hydrogen peroxide; hydroxyl radical; pollution; tree decline

(MS submitted to Ecological Modelling 28 July 2005;

Revised 5 August 2006)

* Corresponding author. Tel: +81-11-706-2268;

fax: +81-11-706.4954;

E-mail address: kubo@ees.hokudai.ac.jp (T. Kubo) 


\section{Abstract}

The present study aimed to evaluate the short-term biomass accumulation of 3 forest trees exposed to wet acidic depositions. A hierarchical Bayesian model of tree 4 growth was developed based on the data of a short-term experiment in which two5 year old Japanese red pine (Pinus densiflora Sieb. et Zucc.) seedlings were exposed 6 to aqueous phase $\mathrm{OH}$ radicals generated by an iron-oxalate- $\mathrm{H}_{2} \mathrm{O}_{2}$ mist (a pseudo7 polluted dew) over two growing periods. We conducted a statistical comparison 8 of tree growth between the control and pollution treatment groups by using the 9 growth model incorporated the random effects due to the unknown characteristics 10 of each seedling. The variability among seedlings is expressed in this model by the posterior probabilistic distributions of unobserved dry weight of a stem cohort before exposure treatment. The analysis of the effects of pollution treatment on the stem growth revealed that this treatment decreases the biomass allocation in the current 14 year stems. However, the effects on the relative growth rate of pre-existing stems were unclear. Based on these results is that, we can speculate that in a polluted environment, the short-term growth of the young stems in the seedlings inhibited western Japan. 


\section{$1 \quad 1$ Introduction}

$2 \quad$ Modelling and statistical analysis using inherent uncertainty and incomplete data

3 have been widely conducted in the field of environmental science, for example, the

4 dynamic vegetation model (Lexer and Höenninger, 2004) and the estimation of phys-

5 iological parameters in lake ecosystems (Malve et al., 2005). A recent trend is the

6 use of Bayesian methods for the statistical modelling of such situation (Clark et al.,

7 2003; Ellison, 2004; Clark, 2005) in which we introduce the prior probabilistic distri-

8 butions of unknown factors, such as the characteristics of unobservable/unobserved

9 experimental materials, transitional changes during experimental period and fluctu-

10 ations in environmental factors.

11 Controlling for unobserved factors is not completely solved in the modelling study

12 of tree growth, whereas many detailed process-based and functional-structured mod-

13 els have been developed (Roux et al., 2001). The detailed tree simulators become

14 more diverse, for example, physiological process-based models such as TREGRO (We-

15 instein and Yanai, 1994; Weinstein et al., 1998; Yun et al., 2001; Laurence et al.,

16 2001); three-dimensional functional-structural tree models such as LIGNUM (Sievänen

17 et al., 1997; Perttunen et al., 1998; Perttunen et al., 2001) and PipeTree (Kubo and

18 Kohyama, 2005). These models that incorporate various physiological processes are 
1 accepted because their usefulness and validity. Consequently, they share a common 2 problem, i.e., model complexity, which can lead to failure, because these models re3 quire large number of parameters including those that are difficult to estimate (e.g. 4 Mäkelä et al., 2000; Radtke and Robinson, 2006).

5 Bayesian inference provides two different approaches to deal with the problem 6 of model complexity: tackling or avoiding. An example of the former approach, in 7 the forest growth is the application of Bayesian modelling to generate the prior and 8 posterior distributions of the parameters used for a complex process-based model 9 on the basis of information from a reliable empirical growth model in lieu of field observations (Radtke and Robinson, 2006). In this case, Bayesian inference functions 11 as a reliable generator of posterior distribution in a very high dimensional parameter 12 space.

The other Bayesian policy, i.e., avoiding complexity, may be utilized if neither 14 sufficient data nor reliable empirical models are available. Clark et al. (2003) em15 phasized the importance of modelling using the uncertainty/variability of parame16 ters while maintaining the simplicity of the model process (in other words, not to 17 increase the complexity of model by adding parameters) in situations where error structure is strongly affected by the differences in individual and site characteristics.

19 Hierarchical Bayesian modelling can facilitate the detection of the manner in which 
1 a focal factor changes the observed pattern in situations where insufficient informa2 tion is available but considerable random effects exist in the data. This is because it expresses the uncertainty of unobserved measurements as the posterior distributions

4 defined by the products of likelihood functions and hierarchical priors (Clark et al., 5 2003; Ellison, 2004; Clark, 2005).

6 The objective of the experiment in which the target data for the current study on 7 the growth of Japanese red pine (Pinus densiflora Sieb. et Zucc., an evergreen conif8 erous tree) seedlings exposed to iron(Fe)-oxalate[(COOH $\left.)_{2}\right]-\mathrm{H}_{2} \mathrm{O}_{2}$ mist, a pseudo 9 polluted dew (Kobayashi et al., 2002), are as follows. This experiment was carried out to detect whether the chemicals present in the wet deposition in and around ur11 ban areas cause a decline of the pine forests in western Japan (refer to Kume et al., 12 2001; Chiwa et al., 2005). Hydrogen peroxide $\left(\mathrm{H}_{2} \mathrm{O}_{2}\right)$ is well known as a reactive 13 oxygen species that forms in plant cells and it affects biochemical processes such as 14 photosynthetic pathways under environmental stresses, such as high light intensity and the presence of air pollutants (Asada, 1999; Halliwell and Gutteridge, 1999; Kondo, 2002). Although gaseous $\mathrm{H}_{2} \mathrm{O}_{2}$ had little effect on plant functions (Polle and Junkermann, 1994), Kume et al. (2001) and Kobayashi et al. (2002) showed that a mist containing iron-oxalate- $\mathrm{H}_{2} \mathrm{O}_{2}$, which simulates polluted morning dew in the declining pine forests, changes some physiological traits, such as needle $\mathrm{CO}_{2}$ 
1 assimilation rate of the Japanese red pine. Kume et al. (2005) suggested that these

2 changes are induced by the system that generates the hydroxyl radical $(\cdot \mathrm{OH})$, the 3 most aggressive oxidant, via a photochemical process in the polluted dew waters on 4 the surface of pine needles.

5 If a "polluted" environment reduces the needle photosynthetic rate and then the 6 accumulation rate of biomas in some form, it is likely to result in either less biomass 7 accumulation at the plant level in the future, i.e., a decline in the growth of tree. 8 This is consistent with field observations at Mt. Gokurakuji, western Japan (Kume 9 et al., 2000a; Kume et al., 2000b; Kume et al., 2006) wherein the photochemical formation of $\cdot \mathrm{OH}$ in morning dew on the needle surfaces was considerably greater 11 in a declining pine stand facing an urban area than in a healthy pine stand on the 12 opposite side of the mountain (Nakatani et al., 2001).

13 In the present study, the objective of the statistical analysis is to quantify the 14 effects of $\cdot$ OH-generating dew on the growth of seedlings based on the data of a 15 pseudo polluted dew exposure experiment (Kobayashi et al., 2002). For this purpose, 16 we focused on the biomass accumulation of stems because long-term tree growth is 17 a consequence of the accumulation of short-term growth of stems (branches and trunks). Since this data appeared to be insufficient to develop a parameter-rich 1 model for tree growth, such as TREGRO, we constructed an ecological model with a 
2 simple process to analyze the growth of pine seedlings under pollution treatment

3 conditions by using a hierarchical Bayesian model based on the structural data of 4 the experimental seedlings.

\section{${ }_{5} \quad 2 \quad$ Experimental methods}

6 This section briefly describes the method of the tree growth experiment under 7 pollution treatment (Kobayashi et al., 2002) and the data structure. Three-year old 8 Japanese red pine seedlings were grown in $\mathrm{O}_{3}$-reduced open-air system chambers 9 placed at a sunny flat site on the Hiroshima University campus, western Japan from 10 August 1999 to 21 September 2000. The details of the pollution treatment and 11 the procedure of the experiment are described previously (Kobayashi et al., 2002).

${ }_{13}(\mathrm{COOH})_{2}$, and $\left.100 \mu \mathrm{M} \mathrm{H}_{2} \mathrm{O}_{2}\right]$ and control mists were harvested the on 21 September

142000 (Fig. 1A). These seedlings were treated with the mists for approximately 14

15 months including two consecutive growing periods. From the first growing period, 16 the needle $\mathrm{CO}_{2}$ assimilation rate of these seedlings were significantly reduced by $\cdot \mathrm{OH}-$ 17 generating iron-oxalate- $\mathrm{H}_{2} \mathrm{O}_{2}$ mist (Kobayashi et al., 2002). Prior to the harvesting of a seedling, its natural height was recorded, and then the above-ground parts 1 were separated into flowers, buds, needles, and stem. The needles and stems were 
2 subdivided according to their age (current-, one-, two- and three-year old). Stems

3 of the same age are referred to as a cohort. More details such as the branching

4 architecture and the connecting structure between the stems of the seedlings were

5 not recorded. The cohort of stems that developed in 1997 is referred to as "cohort

6 1997" which was three years old in September 2000 (refer to Fig. 1A and B). The

7 number of stems in each cohort was counted. The length and diameter of each stem

8 were measured. All organs were dried at $70{ }^{\circ} \mathrm{C}$ and weighed.

\section{$9 \quad 3 \quad$ Modelling}

In order to detect the effects of the $\cdot \mathrm{OH}$-generating mist exposure treatment 11 (pollution treatment) on the growth of pine seedlings, we analyze the data of cohort 121999 (parts existing before exposure) and cohort 2000 (newly developed parts) under 13 the treatment. First, a simple ecological model for the growth of a stem cohort of 14 pine is defined as the frame of subsequent statistical modelling. In the next step, a statistical model to estimate parameters is constructed using the measurements of cohort 1999 and cohort 2000. The conceptual schema and notations for the growth 17 model are shown in Fig. 2.

Our growth model of the stem cohort has the following two components: dry weight increment of cohort 1999 and biomass allocation between cohort 1999 and 
1 cohort 2000 with a fixed ratio. Let $i$ be the index for individual seedlings where $2 i \in\{\mathrm{C} \# 1, \cdots, \mathrm{C} \# 4\}$ for seedlings in control group exposed to the mists containing 3 few $\cdot \mathrm{OH}$, and $i \in\{\mathrm{T} \# 1, \cdots, \mathrm{T} \# 4\}$ for the treatment group exposed to $\cdot \mathrm{OH}$-generating 4 mists (pollution treatment). For a given seedling $i$, the expectation of the dry weight 5 of cohort 1999 in September 2000 (Fig. 1, after exposure) $y_{i}$ is proportional to its dry 6 weight $x_{i}$ in September 1999 (before exposure). We introduce a formula to express 7 this relationship, $\mathrm{E}\left(y_{i}\right)=g_{i} x_{i}$, where $g_{i}$ is the relative growth rate (RGR) of stem 8 cohort 1999. The RGR $g_{i}$ is affected by pollution treatment $g_{i}=\exp \left(\beta_{0}+\beta_{T} T_{i}\right)$, 9 where $\beta_{0}$ and $\beta_{T}$ are the coefficients of constant term and treatment status $T_{i}$, 10 respectively. The value of treatment status $T_{i}$ is set to zero if seedling $i$ is from 11 control group, or to one if it is from the pollution treatment group. Since the dry 12 weight $x_{i}$ of cohort 1999 before the pollution treatment is not observed, we define ${ }_{13} x_{i}$ as a random variable sampled from a probabilistic distribution. Based on the definition of $g_{i}$, a negative $\beta_{T}$ indicates that the stem RGR is decreased by the 15 pollution treatment.

The expectation of the dry weight $z_{i}$ of cohort 2000 in September 2000 is pro17 portional to the growth of cohort 1999. The relationship is expressed as $\mathrm{E}\left(z_{i}\right)=$ ${ }_{18} a_{i}\left(y_{i}-x_{i}\right)$, where $a_{i}$ is referred to as the allocation weight that also include a param1 eter of pollution treatment, $a_{i}=\exp \left(\alpha_{0}+\alpha_{T} T_{i}\right)$, where $\alpha_{0}$ is the baseline parameter 
2 and $\alpha_{T}$ is the coefficient of pollution treatment. If $a_{i}$ is smaller than one, biomass

3 allocation is smaller in cohort 2000 (newly developed stems) than in cohort 1999

4 which was developing before the pollution treatment.

5 A hierarchical Bayesian statistical model is constructed based on the above eco-

6 logical model of stem cohort growth. In Bayesian inference, all parameters (including 7 missing data) are generated by prior distributions (e.g. Rivot et al., 2004; Agarwal 8 et al., 2005; Clark, 2005). To obtain the values of parameters, Gibbs sampling meth9 ods driven by the Markov Chain Monte Carlo (MCMC) calculation generate sample 10 sets from the joint posterior distribution of all parameters (Qian et al., 2003). All variables and parameters are listed in Table 1 with the means and variances of 12 (prior) probabilistic distributions. 14 that the weights of the stem cohorts $\left(z_{i}, y_{i}\right.$, and $\left.x_{i}\right)$ follow this distribution with a 15 variance that is proportional to its mean. The distribution of $z_{i}$, the total weight of 16 cohort 2000 in September 2000, has a mean $a_{i}\left(y_{i}-x_{i}\right)$ and variance that is equal 17 to the mean scaled by the rate parameter $\rho_{z}$, i.e., $a_{i}\left(y_{i}-x_{i}\right) / \rho_{z}$. Here, we introduce 1 a notation $p\left(z_{i} \mid y_{i}, x_{i}, a_{i}, \rho_{z}\right)$ that represents the conditional probability density (or 2 likelihood) of $z_{i}$ given by the Gamma distribution under $\left\{y_{i}, x_{i}, a_{i}, \rho_{z}\right\}$. As in cohort $32000, p\left(y_{i} \mid x_{i}, g_{i}, \rho_{y}\right)$ represents the conditional probability density of the total weight 
$4 y_{i}$ of cohort 1999 in September 2000, given by the Gamma distribution of mean $g_{i} x_{i}$

5 and variance $g_{i} x_{i} / \rho_{y}$.

$6 \quad$ In this growth model, the total weight $x_{i}$ of cohort 1999 in September 1999

7 (before exposure), is defined as a random variable following some appropriate prior

8 distribution. The conditional probability density of $x_{i}, p\left(x_{i} \mid w_{i}, \rho_{x}\right)$, is given by the

9 Gamma distribution as well as by the observed cohort weight $y_{i}$ and $z_{i}$. The prior

10 distribution of $x_{i}$ has mean $w_{i}$ and variance $w_{i} / \rho_{x}$. The individual specific mean $w_{i}$

11 is defined as a combination of measurements and the parameters of pollution effects,

12 that is,

$$
\begin{aligned}
w_{i}= & (\text { mean stem weight of cohort } 2000 \text { of } i) \\
& \times(\text { stem number of cohort } 1999 \text { of } i) \\
& \times \exp \left(-\left(\alpha_{T}+\beta_{T}\right) T_{i}\right)
\end{aligned}
$$

13 which includes the adjustment of the effects of pollution treatment by $\exp \left(-\left(\alpha_{T}+\right.\right.$ $\left.\left.{ }_{14} \beta_{T}\right) T_{i}\right)$ term. This is because the mean stem weight for $x_{i}$ has to be revised when 15 the current-year old stems in 2000 are smaller those in 1999 due to the effects of because the distribution of $x_{i}$ is defined as a prior distribution that requires a hyper 18 parameter $\rho_{x}$ and its hyper prior distribution.

It should be noted that the uncertainty of $x_{i}$ given by its posterior distribution 
also acts as the random effects of seedling $i$ on the growth of $y_{i}$ and $z_{i}$. Crawley (2005) defines random effects in statistical models as they do not influence on the mean but only on the variance of the response variables. Therefore, it should be considered 4 that the posterior distribution of $x_{i}$ represents the mixed effects that influence both 5 the mean and variance of the observed values $y_{i}$ and $z_{i}$ among the seedlings. This is 6 important to detect the effects of pollution treatment under unknown heterogeneity 7 among the experimental seedlings.

Since we do not prior knowledge regarding the parameters to be estimated, the

$$
\begin{aligned}
p\left(\left\{x_{i}\right\}, \boldsymbol{\alpha}, \boldsymbol{\beta}, \boldsymbol{\rho} \mid\{\text { data }\}\right) \propto & \prod_{i} p\left(z_{i} \mid y_{i}, x_{i}, a_{i}, \rho_{z}\right) p\left(y_{i} \mid x_{i}, g_{i}, \rho_{y}\right) p\left(x_{i} \mid w_{i}, \rho_{x}\right) \\
& \times p\left(\alpha_{0}\right) p\left(\alpha_{T}\right) p\left(\beta_{0}\right) p\left(\beta_{T}\right) p\left(\rho_{z}\right) p\left(\rho_{y}\right) p\left(\rho_{x}\right),
\end{aligned}
$$

where $\{$ data $\}$ is defined as $\{$ data $\} \in\left\{\left\{y_{i}\right\},\left\{z_{i}\right\}\right\}$. The MCMC sampling from the Gibbs distribution defined earlier was performed to infer the posterior distribu- 
2 tions of parameters. The sampling was carried out using the Gibbs sampling soft-

3 ware, JAGS-0.90 (developed by M. Plummer, http://www-fis.iarc.fr/〜martyn/

4 software/jags/). The size of sampling was 1000 with a 10 step interval after 40000

5 burn-in steps. The JAGS files for the growth model including the model definition in

6 BUGS code and the data of red pines are available at http://hosho. ees . hokudai.

7 ac.jp/ kubo/forest/redpine/v2006/.

\section{Results and Discussion}

9 Measurements of all the eight pine seedlings in September 2000 are shown in

10 Table 2. Considerable variabilities were observed among the seedlings even within

11 each treatment group. The relationship between the age of stem cohort and its total

12 dry weight shows that with the exception of one seedling, almost all cohorts 2000 in

13 the seedlings of the pollution treatment group are smaller than cohorts 1999. On the

14 other hand, the biomass allocation between cohort 1999 and cohort 2000 is almost

15 equivalent in the control group (Fig. 3). Since the variabilities among the seedlings

16 shown in Table 2 and Fig. 3 cannot be negligible, we will focus on the results from

17 the Bayesian analysis of the parameters for the relative growth rate of stems by

18 incorporating the individual characteristics as random effects.

The means of posterior distributions of the stem dry weight $x_{i}$ of cohort 1999 
1 in September 1999 of seedling $i$ is in range from approximately 2.66 to $6.61 \mathrm{dw} \mathrm{g}$

2 (Fig. 4 and Table 3). While the difference in the means of $x_{i}$ between the treatment 3 groups is unclear, the variance of posterior distributions in the pollution treatment 4 group is considerably greater than that in the control group. This is because they 5 are affected by the fluctuation in the parameters of treatment effects $\alpha_{T}$ and $\beta_{T}$ 6 during MCMC sampling.

$7 \quad$ The convergences of MCMC sampling are assessed by sampling transitions and 8 the density plots of posterior distributions of parameters for the relative growth rate $9 g_{i}$ and relative allocation factor $w_{i}$ (Figs. 5 and 6 ). The $95 \%$ credible interval of $\beta_{T}$, the effects of pollution treatment on RGR, includes $\beta_{T}=0$ (Fig. 5D and Table $113)$. The $95 \%$ credible interval of $\alpha_{T}$, the effects of pollution treatment on biomass 12 allocation, does not include $\alpha_{T}=0$ (Fig. 6D and Table 3).

The most important result of the analysis of the experiment data of pine seedlings 14 with and without $\cdot$ OH-generating mist exposure (Kobayashi et al., 2002) is the detection of the negative effect of pollution treatment on the biomass allocation to the current year stems. This is shown by the posterior distribution of $\alpha_{T}$ (Fig ${ }^{*}$ D and Table 3) generated by the hierarchical Bayesian model with the random effects caused by unobserved factors in each seedling that are expressed by the estimated 19 posterior distribution of $x_{i}$ (Fig. 4). In other words, the variability of $x_{i}$ represents 
1 all the uncertainty in the growth of seedling $i$.

2 By accepting the statistical significance of $\alpha_{T}$, we can evaluate the geometric 3 mean of biomass allocation weight by using the mean values listed in Table 3 . The 4 mean allocation weight of the seedlings in the pollution treatment group is $a_{i}=$ ${ }_{5} \exp (0.27-0.48) \approx 0.81$, i.e., biomass allocation ratio between cohort 1999 and 6 cohort 2000 is approximately $1: 0.81$, while that for controls is $\exp (0.27) \approx 1.31$ in 7 which the allocation ratio is approximately $1: 1.31$. Thus, fraction of youngest stem 8 is smaller in the seedlings exposed to the pollution treatment.

9 On the other hand, we conclude that the analysis cannot detect any negative 10 effects of pollution treatment on stem RGR of cohort 1999. This is because the ${ }_{11} 95 \%$ credible interval of $\beta_{T}$, the effects of pollution treatment on the RGR of two12 year old stems before pollution treatment, includes $\alpha_{T}=0$ (Fig. 5D and Table 3). 13 A possible interpretation of the results is that $\cdot \mathrm{OH}$-generating dews considerably 14 reduce the growth rate of the youngest parts of pine seedlings that have developed 15 after exposure than those of the stems existing before exposure. In agreement with 16 this hypothesis, Kume et al. (2000a) reported that pine trees growing in the declining 17 stands that are subjected to the $\cdot \mathrm{OH}$-generating dew maintained radial growth of the trunk but had a smaller fraction of stem biomass in the current-year-old shoot 19 than those in the non-declining stands. 
If such the difference in the biomass allocation ratio of pine seedlings between

2 the control and pollution treatment groups is due to the exposure treatment, it 3 can be conjectured that that the $\cdot \mathrm{OH}$-generating mist (aqueous-phase $\mathrm{OH}$ radicals)

4 affects not only the short-term responses such as the decreasing in growth rate of the 5 youngest parts at seedling phase but also the biomass accumulation over a longer 6 period by less allocation of biomass to new stems in the life history of the pine 7 tree. This may explain the patterns observed in the declining Japanese red pine 8 forests (e.g. Kume et al., 2000a; Kume et al., 2000b). The wet acidic depositions 9 that generate reactive oxygen species/free radicals from dissolved air pollutants are 10 likely to suppress seedling growth weakly rather than do so rapidly and resulting in 11 the radical death of seedlings. In support of this viewpoint, Yoon et al. (2006) also 12 reported the negative effects of $\cdot \mathrm{OH}$-generating mists on the leaf $\mathrm{CO}_{2}$ assimilation ${ }_{271}$ rate and the stem growth rate in the seedlings of Japanese apricot (Prunus mume), a deciduous broad-leaved species. In the present study, we also demonstrate a new application of Bayesian inference to estimate the tree growth rate from the static and structural data of seedlings ${ }_{275}$ (Fig. 3 and Table 2). Although the data set is characterized by missing measurements ${ }_{276}$ (the weight of stem cohort 1999 in September 1999) and variability due to unknown 277 characteristics of each seedling, we can determine the effects of pollution treatment 


\section{Acknowledgments}

We thank the members and students of Hiroshima University and the Center for Forest Decline Studies for their assistance in the experiments, particularly Dr. Nobutake Nakatani, Mr. Tsuyoshi Hirakawa, Ms. Masayo Abe-Suzuki, Dr. Takayuki Miyake, Dr. Masaaki Chiwa, Ms. Takae Yuhara and Dr. Takami Satomura. Prof. Dr. Hiroshi Sakugawa, Dr. Atsushi Kume and Prof. Dr. Kaneyuki Nakane also supported us and offered advice and suggestions to conduct the experiments. We thank Dr. Maki Suzuki, and Dr. Tetsuo Shirota for their helpful discussion on modelling, Dr. Naoki Tashiro for his several comments on the manuscript. This work was a part of the Core Research for Evolution Science and Technology (CREST), Japan Science and Technology Corporation (JST) and was supported by Grants-in-Aid for Scientific Research from the Ministry of Education, Science and Culture of Japan 
(No.14380244, 15770006, and 18657012) and the Showa Shell Sekiyu Foundation for

the Promotion of Environmental Research.

\section{References}

Agarwal, D. K., Silander, J. A., Gelfand, A. E., Dewar, R. E., Mickelson, J. G., 2005. Tropical deforestation in Madagscar: analysis using hierarchical, spatially explicit, Bayesian regression models. Ecological Modelling 185, 105-131.

Asada, K., 1999. Rapid adaptation of leaves to light environment. In: Watanabe, A., Shinozaki, K., Terashima, I. (Eds.), Environmental responses of plants. Shujunsha, Tokyo, pp. 107-119.

Chiwa, M., Matsuda, T., Nakatani, N., Sueki, Y., Kobayashi, T., Sakugawa, H., 2005. Physiological effects of hydroxyl radical $(\cdot \mathrm{OH})$ generating solution as simulated dew on the needle surfaces of Japanese red pine (Pinus densiflora Sieb. et Zucc.). Phyton 45, 237-244.

Clark, J. S., 2005. Why environmental scientists are becoming Bayesians. Ecology Letters 8, 2-14.

Clark, J. S., Mohan, J., Dietze, M., Ibanez, I., 2003. Coexistence: how to identify trophic trade-offs. Ecology 84, 17-31.

Crawley, M. J., 2005. Statitics, an introduction using R. Wiley.

Ellison, A. M., 2004. Bayesian inference in ecology. Ecology Letters 7, 509-520.

Halliwell, B., Gutteridge, J., 1999. Free radicals in biology and medicine (3rd ed). Oxford University Press, New York.

Kobayashi, T., Nakatani, N., Hirakawa, T., Suzuki, M., Miyake, T., Chiwa, M., Yuhara, T., Hashimoto, N., Inoue, K., Yamamura, K., Agus, N., Sinogaya, J., Nakane, K., Kume, A., Arakaki, T., Sakugawa, H., 2002. Variation in $\mathrm{CO}_{2}$ assimilation rate induced by simulated dew waters with different sources of hydroxyl radical $(\cdot \mathrm{OH})$ on the needle surfaces of Japanese red pine (Pinus densiflora Sieb et Zucc.). Environmental Pollution 118, 383-391.

Kondo, N., 2002. Uptake, metabolism, and detoxification of sulfur dioxide. In: Omasa, K., Saji, H., Youssefian, S., Kondo, N. (Eds.), Air pollution and plant biotechnology. Springer-Verlag, Tokyo, pp. 179-199.

Kubo, T., Kohyama, T., 2005. Abies population dynamics simulated using a functional-structural tree model. Ecological Research 20, 255-269.

Kume, A., Arakaki, T., Tsuboi, N., Suzuki, M., Kuramoto, D., Nakane, K., Sakugawa, H., 2001. Harmful effects of radicals generated in polluted dew on the needles 
of Japanese Red Pine (Pinus densiflora). New Phytologist 152, 53-58.

Kume, A., Hanba, Y. T., Nakane, K., Sakurai, N., Sakugawa, H., 2006. Seasonal changes in needle water content and needle ABA concentration of Japanese red pine, Pinus densiflora, in declining forests on Mt. Gokurakuji, Hiroshima prefecture, Japan. Journal of Plant Research 119, 231-238.

Kume, A., Nakane, K., Sakugawa, H., 2005. Complex environmental factors affecting the decline of Pinus densiflora in the Seto Inland Sea area of western Japan. Journal of Agricultural Meteorology 60, 1149-1152.

Kume, A., Osaki, E., Nakane, K., Sakugawa, H., 2000a. Whole tree decline process of Pinus densiflora and Abies firma in air polluted areas. In: Akimoto, H., Kajii, Y., Kobayashi, T., Sakugawa, H. (Eds.), Oxidants/acidic species and forest decline in east Asia. Center for Forest Decline Studies, Higashi-Hiroshima, pp. 99-102.

Kume, A., Tsuboi, N., Satomura, T., Suzuki, M., Chiwa, M., Nakane, K., Sakurai, N., Horikoshi, T., Sakugawa, H., 2000b. Physiological characteristics of Japanese red pine, Pinus densiflora Sieb et Zucc. in declined forests at Mt. Gokurakuji in Hiroshima Prefecture, Japan. Trees 14, 305-311.

Laurence, J., Retzlaff, W., Kern, J., Lee, E., Hogsett, W., Weinstein, D., 2001. Predicting the regional impact of ozone and precipitation on the growth of loblolly pine and yellow-poplar using linked TREGRO and ZELIG models. Forest Ecology and Management 146, 247-263.

Lexer, M. J., Höenninger, K., 2004. Effects of error in model input: experiments with a forest patch model. Ecological Modelling 173, 159-176.

Mäkelä, A., Landsberg, J., Ek, A. R., Burk, T. E., Ter-Mikaelian, M., Agren, G. I., Oliver, C. D., Puttonen, P., 2000. Process-based models for forest ecosystem management: current state of the art and challenges for practical implementation. Tree Physiology 20, 289-298.

Malve, O., Laine, M., Haario, H., 2005. Estimation of winter respiration rates and prediction of oxygen regime in a lake using baysian inference. Ecological Modelling 182, 183-197.

Nakatani, N., Miyake, T., Chiwa, M., Hashimoto, M., Arakaki, T., Sakugawa, H., 2001. Photochemical formation of $\mathrm{OH}$ radicals in dew formed on the pine needles at Mt. Gokurakuji. Water Air Soil Pollution 130, 397-402.

Perttunen, J., Nikinmaa, E., Lechowicz, M., Sievänen, R., Messier, C., 2001. Application of the functional-structural tree model LIGNUM to sugar maple saplings (Acer saccharum Marsh) growing in forest gaps. Annals of Botany 88, 471-481.

Perttunen, J., Sievänen, R., Nikinmaa, E., 1998. LIGNUM: a model combining the structure and the functioning of trees. Ecological Modelling 108, 189-198.

Polle, A., Junkermann, W., 1994. Does atmospheric hydrogen peroxide contribute 
to damage to forest tree? Environmental Science and Technology 28, 812-815.

Qian, S. S., Stow, C. A., Borsuk, M. E., 2003. On monte carlo methods for Bayesian inference. Ecological Modelling 159, 269-277.

Radtke, P. J., Robinson, A. P., 2006. A Bayesian strategy for combining predictions from empirical and process-based models. Ecological Modelling 190, 287-298.

Rivot, E., Prévost, E., Parent, E., Baglinière, J. L., 2004. A Bayesian state-space modelling framework for fitting a salmon stage-structured population dynamic model to multiple time series of field data. Ecological Modelling 179, 463-485.

Roux, X. L., Lacointe, A., Escobar-Gutiérrez, A., Dizès, S. L., 2001. Carbon-based models of individual tree growth: A critical appraisal. Annals of Forest Science 58, 469-506.

Sievänen, R., Nikinmaa, E., Perttunen, J., 1997. Evaluation of importance of sapwood senescence on tree growth using the model LIGNUM. Silva Finica 31, 329340.

Weinstein, D., Samuelson, L., Arthur, M., 1998. Comparison of the response of red oak (Quercus rubra) seedlings and mature trees to ozone exposure using simulation modeling. Environmental Pollution 102, 307-320.

Weinstein, D. A., Yanai, R. D., 1994. Integrating the effects of simultaneous multiple stresses on plants using the simulation model TREGRO. Journal of Environmental Quality 23, 418-428.

Yoon, J., Abe-Suzuki, M., Eko, P., Tamai, H., Hanamitsu, S., Nakane, K., 2006. Negative effects of hydroxyl radical-generating mists (simulated dew water) on the photosynthesis and growth of japanese apricot seedlings (Prunus mume). Ecological Research 21, 117-125.

Yun, S.-C., Park, E. W., Laurence, J. A., 2001. Simulation of 1-year-old Populus tremuloides response to ozone stress at Ithaca, USA, and Suwon, Republic of Korea. Environmental Pollution 112, 253-260. 
Table 1 Variables and parameters of the growth model based on the stem biomass

\begin{tabular}{|c|c|c|c|c|}
\hline & variable / parameter & $\begin{array}{l}\text { distribution / } \\
\text { prior distribution }\end{array}$ & mean & variance \\
\hline$x_{i}$ & $\begin{array}{l}\text { total weight of cohort } 1999 \\
\text { in September } 1999\end{array}$ & Gamma & $w_{i}$ & $w_{i} / \rho_{x}$ \\
\hline$y_{i}$ & $\begin{array}{l}\text { total weight of cohort } 1999 \\
\text { in September } 2000\end{array}$ & Gamma & $g_{i} x_{i}$ & $g_{i} x_{i} / \rho_{y}$ \\
\hline$z_{i}$ & $\begin{array}{l}\text { total weight of cohort } 2000 \\
\text { in September } 2000\end{array}$ & Gamma & $a_{i}\left(y_{i}-x_{i}\right)$ & $a_{i}\left(y_{i}-x_{i}\right) / \rho_{z}$ \\
\hline$\alpha_{0}$ & $\begin{array}{l}\text { allocation parameter } \\
\text { (constant component) }\end{array}$ & Gaussian & 0 & 1 \\
\hline$\alpha_{T}$ & $\begin{array}{l}\text { allocation parameter } \\
\text { (treatment component) }\end{array}$ & Gaussian & 0 & 1 \\
\hline$\beta_{0}$ & $\begin{array}{l}\text { growth rate parameter } \\
\text { (constant component) }\end{array}$ & Gaussian & 0 & 1 \\
\hline$\beta_{T}$ & $\begin{array}{l}\text { growth rate parameter } \\
\text { (treatment component) }\end{array}$ & Gaussian & 0 & 1 \\
\hline$\rho_{x}$ & variance parameter of $x_{i}$ & Gamma & 1 & $10^{3}$ \\
\hline$\rho_{y}$ & variance parameter of $y_{i}$ & Gamma & 1 & $10^{3}$ \\
\hline$\rho_{z}$ & variance parameter of $z_{i}$ & Gamma & 1 & $10^{3}$ \\
\hline
\end{tabular}


Table 2 Stem specifications of all the experimental Japanese red pine seedlings measured at the end of the exposure experiment in September 2000.

\begin{tabular}{|c|c|c|c|c|c|c|c|c|}
\hline & \multicolumn{4}{|c|}{ Treated } & \multicolumn{4}{|c|}{ Control } \\
\hline & $\mathrm{T} \# 1$ & $\mathrm{~T} \# 2$ & $\mathrm{~T} \# 3$ & $\mathrm{~T} \# 4$ & C\#1 & $\mathrm{C} \# 2$ & $\mathrm{C \# 3}$ & $\mathrm{C} \# 4$ \\
\hline height of seedling & 1.08 & 0.94 & 1.30 & 1.27 & 1.12 & 1.16 & 1.11 & $(\mathrm{NA})^{\dagger}$ \\
\hline \multicolumn{9}{|l|}{ Total weight of } \\
\hline stem & 107.4 & 94.1 & 130.8 & 135.9 & 150.9 & 135.0 & 147.2 & 131.4 \\
\hline $\begin{array}{r}(\mathrm{dw} g) \\
\text { needle }\end{array}$ & 135.1 & 157.7 & 107.8 & 135.5 & 127.2 & 110.6 & 113.2 & 136.2 \\
\hline flower \& vegetative bud & 1.9 & 2.4 & 1.7 & 1.4 & 2.6 & 2.9 & 3.6 & 0.7 \\
\hline $\begin{array}{l}(\mathrm{dw} g) \\
\text { root } \\
(\mathrm{dw} g)\end{array}$ & 135.1 & 169.6 & 191.5 & 108.1 & 93.6 & 211.2 & 168.1 & 137.1 \\
\hline \multicolumn{9}{|l|}{ Cohort 2000} \\
\hline number of stem & 65 & 113 & 46 & 77 & 121 & 62 & 113 & 58 \\
\hline mean stem weight & 0.27 & 0.15 & 0.35 & 0.32 & 0.20 & 0.37 & 0.22 & 0.53 \\
\hline mean stem length & 72 & 53 & 65 & 106 & 64 & 109 & 72 & 141 \\
\hline \multicolumn{9}{|l|}{ Cohort 1999} \\
\hline number of stem & 8 & 16 & 8 & 17 & 15 & 14 & 15 & 11 \\
\hline $\begin{array}{r}\text { mean stem weight } \\
(\mathrm{dw} g)\end{array}$ & 3.53 & 0.95 & 3.98 & 2.19 & 1.74 & 1.64 & 1.43 & 2.28 \\
\hline mean stem length & 177 & 100 & 188 & 142 & 120 & 116 & 92 & 121 \\
\hline \multicolumn{9}{|l|}{ Cohort 1998} \\
\hline number of stem & 1 & 6 & 1 & 1 & 3 & 8 & 5 & 4 \\
\hline $\begin{array}{r}\text { mean stem weight } \\
(\mathrm{dw} g)\end{array}$ & 30.54 & 4.92 & 44.10 & 37.60 & 15.60 & 4.78 & 7.62 & 7.58 \\
\hline $\begin{array}{r}\text { mean stem length } \\
(\mathrm{mm})\end{array}$ & 334 & 233 & 395 & 428 & 342 & 177 & 235 & 204 \\
\hline \multicolumn{9}{|l|}{ Cohort 1997} \\
\hline number of stem & 1 & 1 & 1 & 1 & 1 & 1 & 1 & 1 \\
\hline stem weight & 31.10 & 33.00 & 38.60 & 36.70 & 54.10 & 51.10 & 62.90 & 45.50 \\
\hline $\begin{array}{r}\text { stem length } \\
(\mathrm{mm}) \\
\end{array}$ & 254 & 289 & 243 & 272 & 342 & 397 & 408 & 343 \\
\hline
\end{tabular}

$\dagger$ unmeasured. 
Table 3 Mean, 95\% credible interval and standard deviation of the posterior distributions of parameters.

\begin{tabular}{crrr}
\hline parameter & mean & {$[2.5 \%, 97.5 \%]$} & $\mathrm{SD}$ \\
\hline$\alpha_{0}$ & 0.27 & {$[0.05,0.47]$} & 0.11 \\
$\alpha_{T}$ & -0.48 & {$[-0.79,-0.15]$} & 0.16 \\
$\beta_{0}$ & 1.71 & {$[1.42,1.99]$} & 0.15 \\
$\beta_{T}$ & 0.23 & {$[-0.98,1.80]$} & 0.66 \\
$\rho_{x}$ & 4.35 & {$[0.55,22.49]$} & 6.03 \\
$\rho_{y}$ & 35.84 & {$[0.24,211.84]$} & 56.69 \\
$\rho_{z}$ & 1.06 & {$[0.23,2.58]$} & 0.60 \\
$x_{\mathrm{T \# 1}}$ & 4.54 & {$[0.83,11.78]$} & 2.58 \\
$x_{\mathrm{T \# 2}}$ & 2.66 & {$[0.49,6.44]$} & 1.47 \\
$x_{\mathrm{T \# 3}}$ & 5.27 & {$[0.93,13.53]$} & 2.98 \\
$x_{\mathrm{T \# 4}}$ & 6.61 & {$[1.18,16.31]$} & 3.69 \\
$x_{\mathrm{C \# 1}}$ & 4.44 & {$[2.70,6.27]$} & 0.91 \\
$x_{\mathrm{C \# 2}}$ & 4.34 & {$[3.11,6.02]$} & 0.78 \\
$x_{\mathrm{C \# 3}}$ & 3.75 & {$[2.53,5.15]$} & 0.68 \\
$x_{\mathrm{C \# 4}}$ & 4.75 & {$[3.41,6.55]$} & 0.83 \\
\hline
\end{tabular}




\section{Figure Legends}

Fig. 1 (A) Schema of time course of the pseudo polluted mist exposure experiment.

The range of the "exposure experiment" indicates the duration of exposure of the Japanese red pine were seedlings to $\cdot \mathrm{OH}$-generating iron-oxalate- $\mathrm{H}_{2} \mathrm{O}_{2}$ and control mists in open-air system chambers. Downward solid arrow on September 2000 indicates the termination of treatment (seedlings were harvested). Seed germination has occurred in spring, 1997. The buds in the shoot tip have sprouted in spring and develop by the later part of each growing season. The elongation season of the stem cohort of year $j$ is indicated as the durations "cohort $j$ " along with "age" (defined in the text) in September 2000. (B) Schema of the relationship between shoot structure and stem cohort in a pine seedling.

Fig. 2. Schema of the growth model of a pine stem in the $\cdot \mathrm{OH}$-generating mist exposure experiment. The shaded regions in cylinders indicate the growth in year 2000. In the growth process of seedling $i$, the observed total dry weight of cohort $1999\left(y_{i}\right)$ in September 2000 depends on that in September $1999\left(x_{i}\right)$ which is not observed. Biomass allocation process sets the total dry weight of cohort 2000 in September $2000\left(z_{i}\right)$ that depends on the growth of cohort 1999, $y_{i}-x_{i}$. The prior distribution of $x_{i}$ is a function of the stem population of the current-year, i.e., cohort 
2000.

Fig. 3. Observed cohort structure of stem biomass in pine seedlings exposed to $\cdot \mathrm{OH}-$ generating and control mists at the end point of the exposure experiment (September 2000). The horizontal axis indicates the year of emergence of the stem cohort (group of stems of the same age), while the vertical axis indicates total dry weight of the stem cohort.

Fig. 4. Posterior distributions of total dry weight of stem cohort 1999 in September $1999 x_{i}$. Since $x_{i}$ is unobserved, the posterior distribution is generated from the prior distribution with an individual-specific mean and the variance parameter $\rho_{x}$ shared among all seedlings (refer to Table 1).

Fig. 5. MCMC step traces (A and C) and posterior distributions (B and D) of the growth parameters, $\beta_{0}$ and $\beta_{T}$. The $95 \%$ credible interval of the treatment effects, $\beta_{T}$, includes $\beta_{T}=0$ (refer to Table 3 ).

Fig. 6. MCMC step traces (A and $\mathrm{C}$ ) and posterior distributions (B and $\mathrm{D}$ ) of the biomass allocation parameters, $\alpha_{0}$ and $\alpha_{T}$. The $95 \%$ credible interval of the treatment effects, $\alpha_{T}$, includes $\alpha_{T}=0$ (refer to Table 3 ). 
Fig.1

A

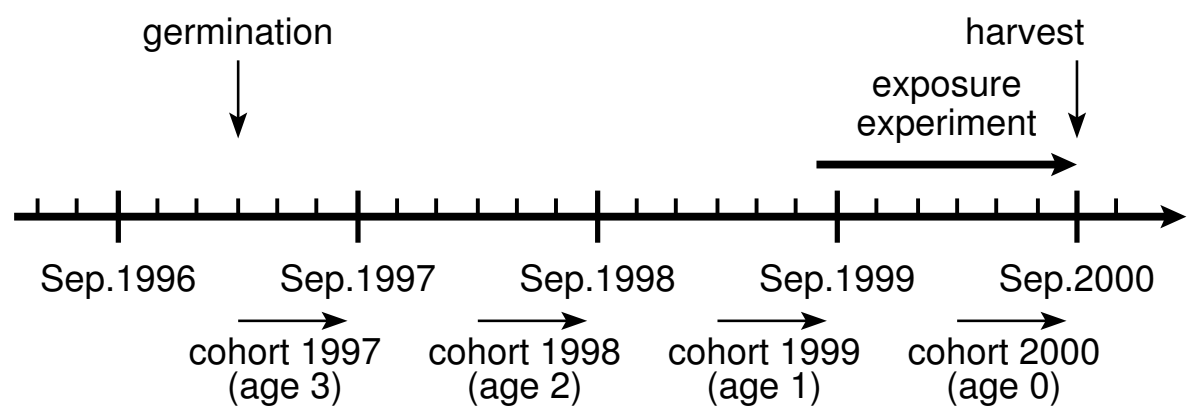

B

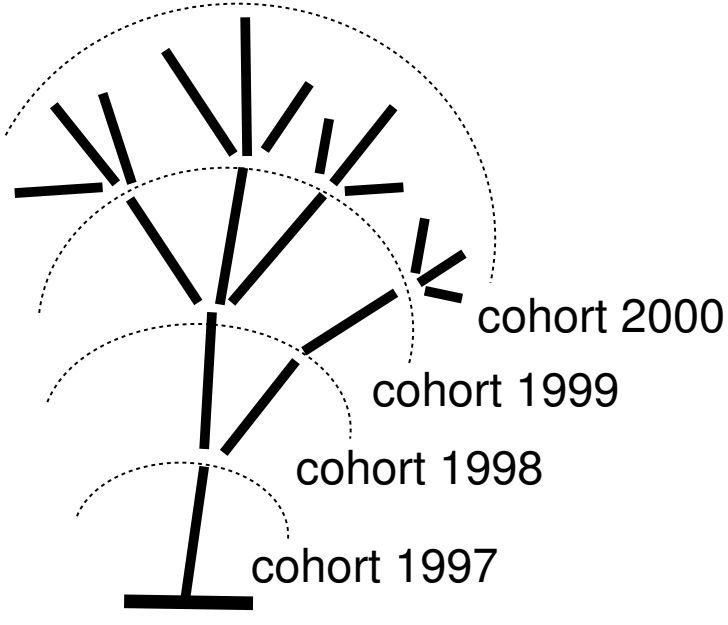


Fig.2

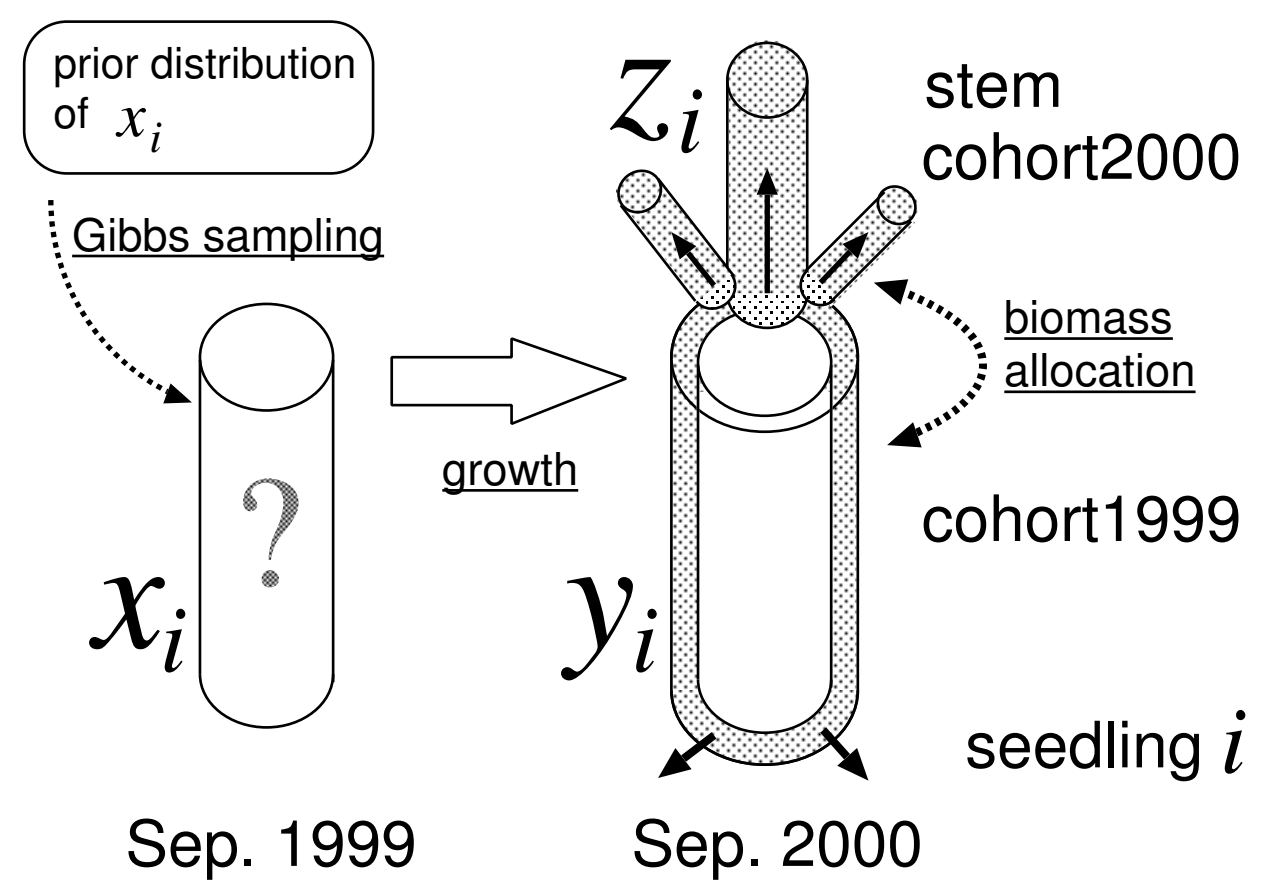


Fig.3

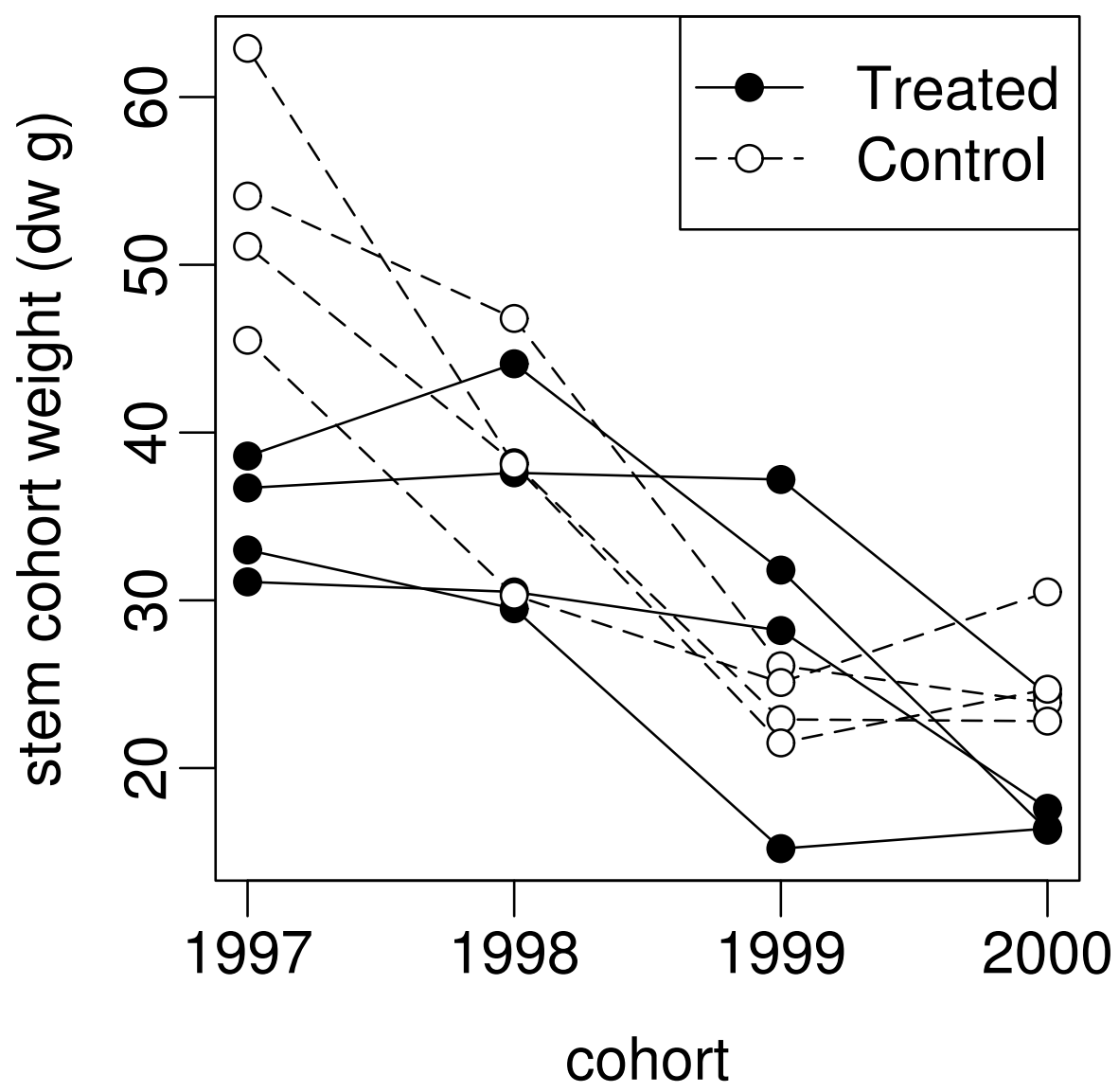


Fig.4

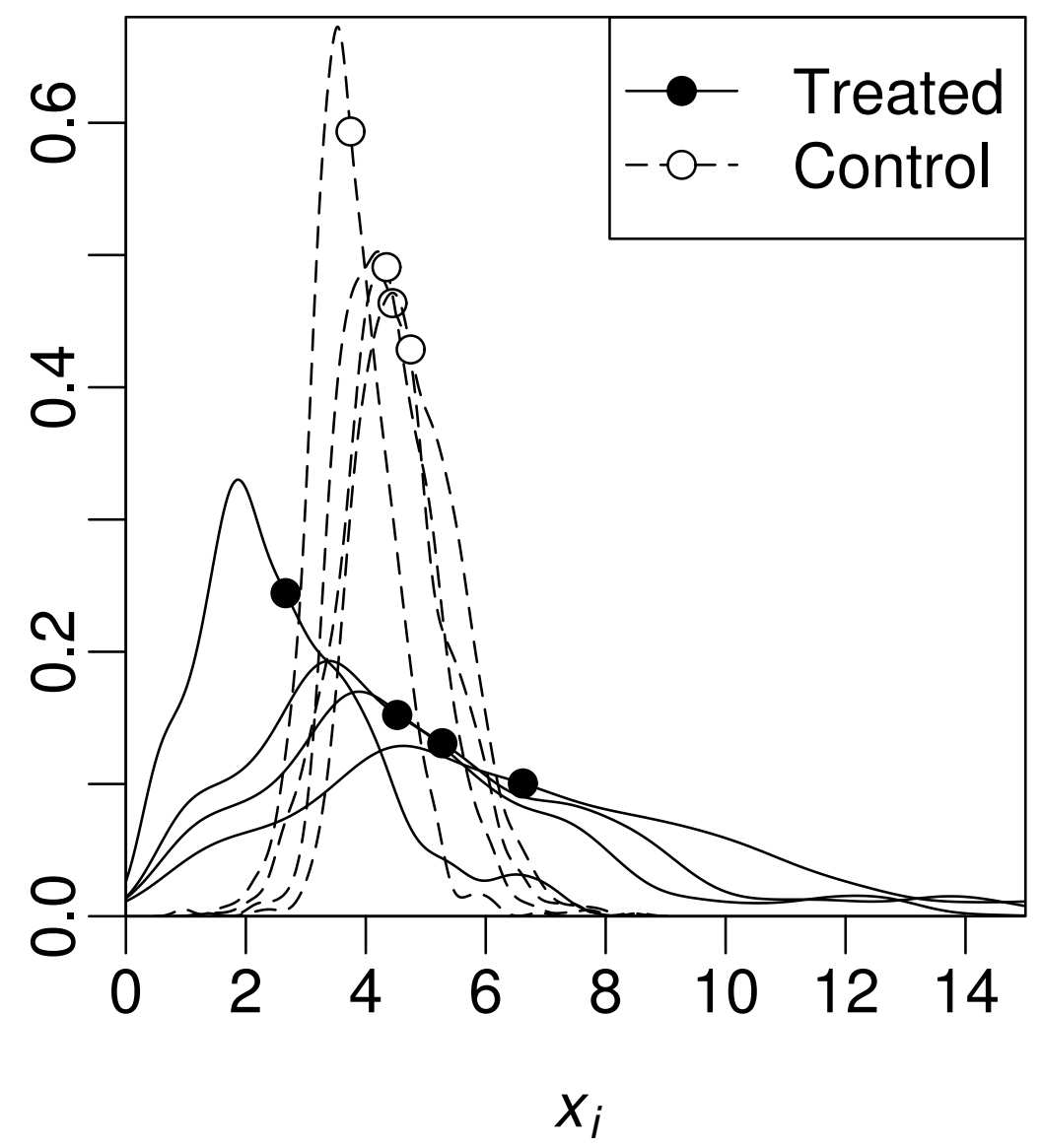


Fig.5
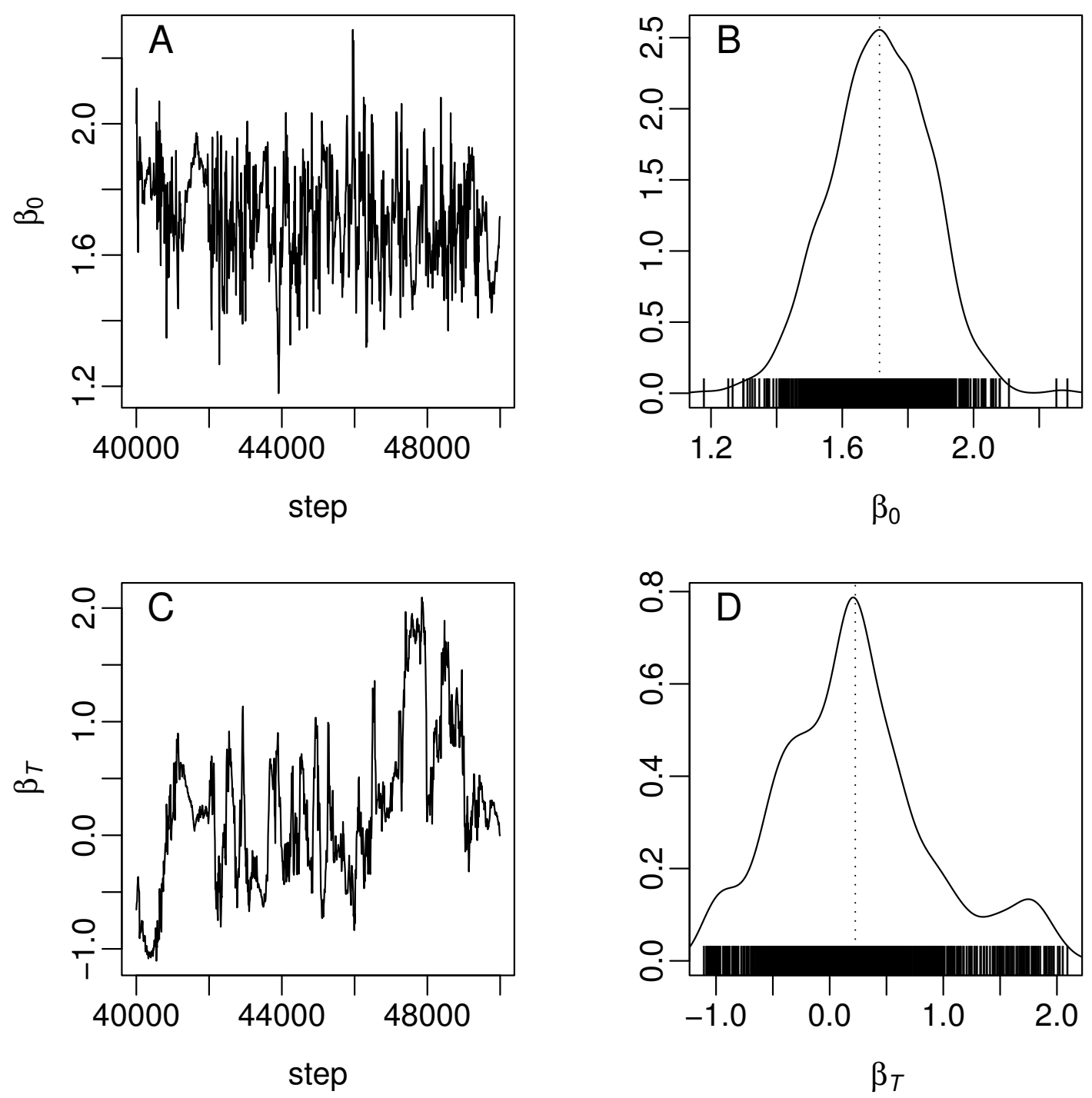
Fig.6
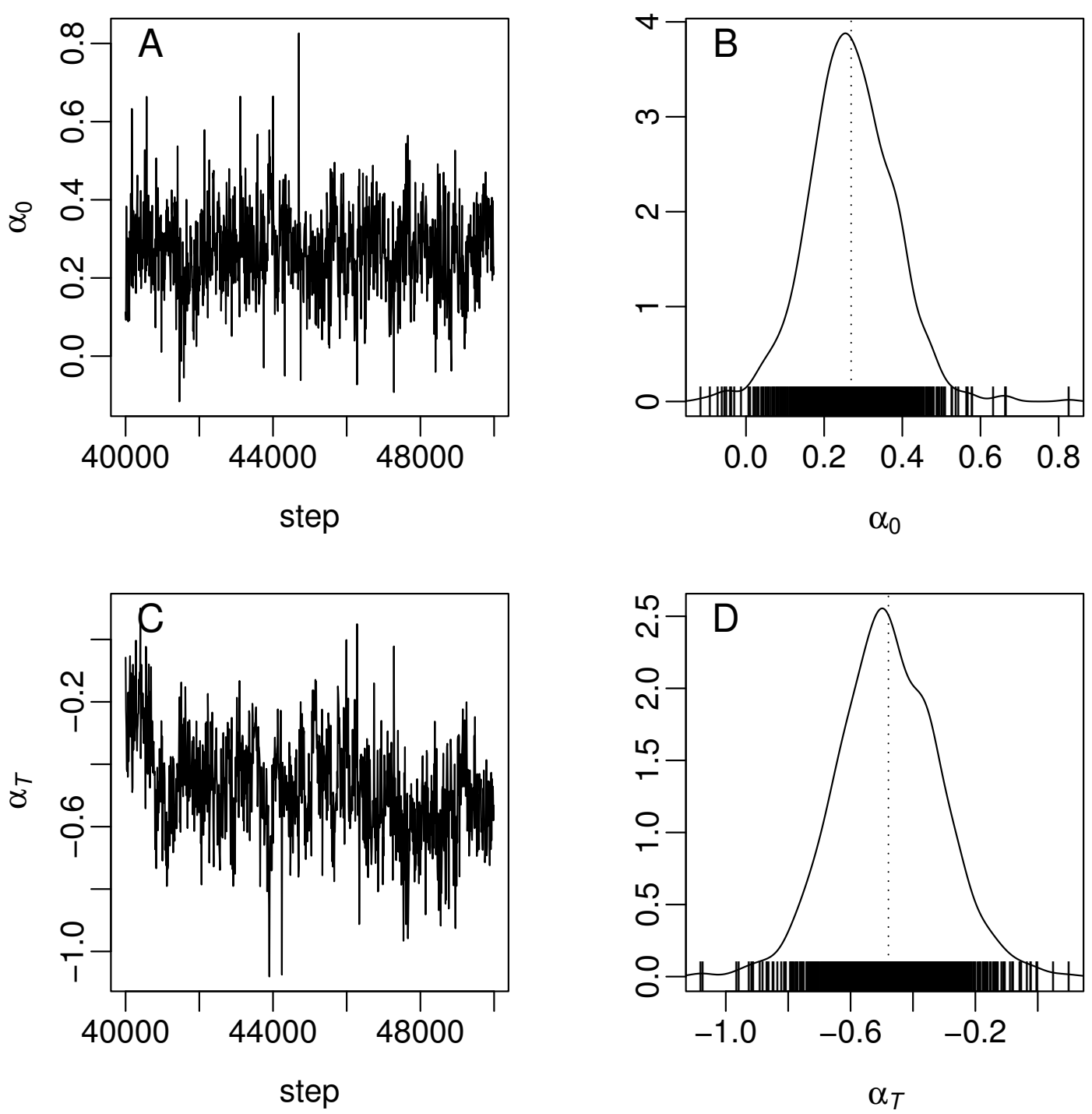